\title{
GENETIC RESISTANCE TO GREENBUG IS EXPRESSED WITH HIGHER CONTENTS OF PROTEINS AND NON-STRUCTURAL CARBOHYDRATES IN WHEAT SUBSTITUTION LINES
}

\author{
A.M. CASTRO ${ }^{1,2, *}$, A.A. CLÚA ${ }^{1}$, D.O. GIMENEZ ${ }^{1}$, E. TOCHO ${ }^{1,2}$, \\ M.S. TACALITI ${ }^{1}$, M. COLLADO ${ }^{1}$, A. WORLAND ${ }^{\dagger}$, R. BOTTINI $^{2,4}$ \\ AND J.W. SNAPE ${ }^{3}$ \\ ${ }^{1}$ Department of Biological Sciences, Faculty of Agronomy, National University of La Plata, CC31, \\ 1900-La Plata, Argentina \\ ${ }^{2}$ National Council of Scientific Research (CONICET) \\ ${ }^{3}$ John Innes Centre, Colney, Norwich NR4 7UH, UK \\ ${ }^{4}$ Faculty of Agricultural Science, National University of Cuyo, Almirante Brown 500, \\ M5528AHB Chacras de Coria, Argentina \\ *E-mail: amcastro@isis.unlp.edu.ar
}

\begin{abstract}
This paper studied the endogenous levels of reduced, non-reduced, total non-structural carbohydrates, soluble proteins and biomass in aerial and rooting structures of bread wheat, Triticum aestivum $(2 \mathrm{n}=6 \mathrm{x}=42)$, in response to aphids, as a first step for understanding the cascade of transductional events that may account for antixenosis, antibiosis and tolerance to greenbug. Up to now, few studies have been made on the relationship between aphid resistance and these traits. A set of wheat intervarietal chromosome substitution lines, with "Chinese Spring" (CS, a greenbug susceptible line) as a recipient and a synthetic wheat (Triticum dicoccum $\times$ T tauschii, $=[\mathrm{Syn}]$ ) as the donor, and both parents were used. Plants were cultivated in hydroponic solutions to the fully expanded 3rd leaf stage. Half of the plants of every genotype were infested $72 \mathrm{~h}$ with greenbugs, and the remaining uninfested plants were used as controls. Carbohydrate and protein contents and dry matter mass were determined for aerial and root tissues Lines $5 \mathrm{~A}$ and $6 \mathrm{~A}$ had lower aerial, root and, consequently, total dry weights in both control and infested plants. These lines have been previously reported to be antixenotic against greenbug and Russian Wheat Aphid (RWA), implying these lines carry genes for constitutive defences. Four substitution lines (1A, 1B, 7B and 7D) showed significant increases in protein content when infested, compared to their controls and to the CS susceptible parent. Considering that these substitution lines have been previously reported to reduce greenbug and RWA fertilities and longevities, the antibiotic
\end{abstract}

$\dagger$ Deceased 
resistance to greenbugs may be related to gene expression for enhanced protein levels. Most of the D genome substitution lines showed an increase of total root carbohydrates with the greatest increase in total root and aerial carbohydrates under infestation in the $1 \mathrm{D}$ and $6 \mathrm{D}$ substitution lines. Since these lines have been reported as being tolerant to greenbug, their highest carbohydrate contents probably protect them against biotic stress by enhancing growth. Greenbug resistance genes have been mapped only on the 1A, 6A, 7A and 7D chromosomes. Nonetheless, it was possible to identify other substitution lines that showed effects in the photosynthesis, the $\mathrm{C}$ and $\mathrm{N}$ metabolisms in the cascade of transductional signals that account for antixenosis, antibiosis and tolerance to greenbug in wheat

Keywords: greenbug, host plant resistance, non-structural carbohydrates - proteins, Schizaphis graminum, substitution lines, wheat

\section{INTRODUCTION}

Greenbug (Schizaphis graminum Rond) is one of the most economically important insect pests of wheat, It causes decreases in yield and even seedling death, depending on the intensity and the moment of infestation, In susceptible cultivars greenbug infestation diminishes total root biomass, and volume, thereby reducing the capacity for water and mineral uptake Castro et al. 1988). After 4 days of infestation it leads to shorter leaves decreasing leaf area Burton 1986, Castro et al. 1994) and reducing photosynthesis Ryan et al. 1987). In susceptible genotypes of barley, oat and sorghum, greenbug inhibits differentiation of new leaf primordia and nodal roots after $48 \mathrm{~h}$ of infestation (see Castro et al, 2001). It has been claimed that these alterations in aerial and root growth were consequence of disturbances in nutrient uptake and transport, (Giménez et al. 1990), suggesting that greenbug induces systemic damage Giménez et al. 1997). Accordingly, tolerant cultivars of barley and wheat showed no decrease in growth or production under aphid infestation Castro et al. 1988, 2001). These previous results are consistent with those found in studies of plant responses to insect attack in the Nicotiana attenuata-Manduca sexta system Hermsmeier et al 2001). Changes in the metabolism of infested plants involved constitutive and induced defences, and these responses are based on very complex transcriptional regulation that include genes coding for both primary and secondary metabolites, wound- and jasmonate-elicited responses induced or repressed photosynthesis, carbon and nitrogen metabolisms Kessler and Baldwin 2001, 2002).

The genetic control of the synthesis of reducing, non-reducing and total nonstructural carbohydrates and soluble proteins in aerial and root tissues of wheat seedlings has been reported in a set of substitution lines Clúa et al. 2002). The same set was used to study the chromosomal effects on the different mechanisms of greenbug resistance Castro et al 2001). These authors reported the Chinese Spring/Synthetic substitution lines that contributed the highest levels of antixenosis (5A and 6A), antibiosis (1A, 1B and homoeologous group 7 chromosome) and 
tolerance (1D and 6D) to greenbug. However, to date aphid $\mathrm{R}$ genes in wheat have been located only on the 1A, 1D, 7D (McIntosh et al.2003), 7A (Boyko et al. 2004) and $6 \mathrm{~A}$ chromosomes Castro et al. 2005). Since, the relationship between wheat chromosomes involved in the control of total biomass, contents of carbohydrates and proteins, and the plant responses to aphids has not been studied, the aim of this paper was to evaluate these plant traits as a first step towards the knowledge of the relationship between aphid resistance and these three metabolisms in the cascade of events that account for antixenosis, antibiosis and tolerance to greenbug. By restricting the variability to a single chromosome, it should be possible to isolate the effects of chromosomes carrying genes involved with photosynthesis, and with $\mathrm{C}$ and $\mathrm{N}$ metabolisms in the infested plants.

\section{MATERIALS AND METHODS}

\section{Plant Material}

A set of intervarietal chromosome substitution lines of wheat, Triticum aestivum $\mathrm{L}$, Law and Worland 1996) was used in the current research The lines 2A, 4A, 7A, $2 \mathrm{~B}$ and $6 \mathrm{~B}$ were not included because the molecular characterizations of these chromosomes were not correct "Chinese Spring" (CS) was the recipient variety into which chromosomes from a synthetic wheat $(T$ dicoccum $\mathrm{x} T$ tauschii $=$ Syn) were introduced. Two hundred seeds of each of the 16 substitution lines and of the parental lines were sown singly in $20 \mathrm{ml}$ plastic vials perforated at the base, on a substrate of vermiculite. The vials were then placed in trays under natural conditions of light and temperature in a glasshouse, in La Plata, Argentina ( $34^{\circ} 55^{\prime} \mathrm{SL}, 57^{\circ} 57^{\prime}$ WL). The trays were filled with nutrient solution Hoagland and Arnon 1959) to enable a free supply of water and minerals and to maintain the volume constant along the experiments.

\section{Source of Aphids}

Greenbugs were collected from wheat plants in the vicinity of Tres Arroyos, Argentina (38 $\left.20^{\prime} \mathrm{SL}, 60^{\circ} 15^{\prime} \mathrm{WL}\right)$, and reared under controlled conditions. The clone aisolated from this population used in the trail was characterized as biotype C Castro et al. 2004).

\section{Assay Procedures}

The responses of wheat plants to aphid infestation were evaluated when plants had reached the fully expanded 3rd leaf stage. Half of the plants of every genotype were transferred to another tray and infested during $72 \mathrm{~h}$ with 10 adult aphids per plant. The remaining uninfested plants were used as controls. Afterwards, aphids were removed, plants were harvested and divided into aerial and root tissues and the fresh weight of each portion was determined Four plants of every genotype 
in each treatment were sampled together, representing one replicate. At least 20 replicates per genotype and treatment were analysed for protein (Bradford 1976) and carbohydrate contents Cronin and Smith 1979). The remaining aerial and root biomass of the 18 genotypes was oven dried at $60^{\circ} \mathrm{C}$ until constant weight, and root (RDW) and aerial dry weights (ADW) were determined ANOVA was applied for all the parameters studied, and Duncan's test was used to determine significant differences between means (SAS 1998).

\section{RESULTS AND DISCUSSION}

There were few significant differences in RDW between control or infested plants of the parental varieties and the corresponding substitution lines. The infestation caused an increase in the RDW of both parental varieties and in most of the substitution lines. The 7B substitution line showed a significantly higher RDW than parental varieties either with or without infestation (Table 1) and the 5A and 6A substitution lines showed a significantly lower RDW compared to the parental controls and infested plants. The aerial dry weight (ADW) and the total dry weight (TDW) were reduced by greenbug feeding in most of the substitution lines, nonetheless, these differences were not significantly different, except for $5 \mathrm{~A}$ and $6 \mathrm{~A}$ substitution lines that showed significantly lower ADW and TDW

Table 1. Root (RDW), aerial (ADW), and total dry weights (TDW) of 16 wheat substitution lines and both parents (CS and Syn), subjected to aphid infestation and in uninfested control plants

\begin{tabular}{|c|c|c|c|c|c|c|}
\hline \multirow[t]{2}{*}{ Lines } & \multicolumn{2}{|l|}{ RDW } & \multicolumn{2}{|l|}{ ADW } & \multicolumn{2}{|l|}{ TDW } \\
\hline & Control & Infested & Control & Infested & Control & Infested \\
\hline $1 \mathrm{~A}$ & 508efgh & 524defg & 1254abcdefg & 1314abcd & 1762abcdefghi & 1838abcde \\
\hline $3 \mathrm{~A}$ & $558 \mathrm{bcdef}$ & 580 bcde & 1214bcdefgh & 1224bcdefgh & 1772abcdefgh & 1804abcdefg \\
\hline $5 \mathrm{~A}$ & 402ijk & 434hij & 9600 & $962^{\circ}$ & 1362mopq & 1416mnop \\
\hline $6 \mathrm{~A}$ & 412ijk & 458ghij & 818op & 824op & 1230pqr & 1272opqr \\
\hline $1 \mathrm{~B}$ & 454ghij & 486fghi & 996 klmn & 1040ijklmn & 14501mno & 1526jklmn \\
\hline $3 \mathrm{~B}$ & 552 bcdef & $558 \mathrm{bcdef}$ & 1218 bcdefgh & 1134 fghijkl & 1770abcdefgh & 1692defghijk \\
\hline $4 B$ & $522 \mathrm{defg}$ & $568 \mathrm{bcdef}$ & 1282abcdef & $1326 \mathrm{abcd}$ & 1804abcdefgh & $1894 \mathrm{abc}$ \\
\hline $5 \mathrm{~B}$ & 516defgh & 536defg & 1130fghijkl & 1042 ijkllmn & 1646efghijkl & 1578hijklm \\
\hline $7 \mathrm{~B}$ & 624ab & $636 a$ & 1200 cdefg & 1220 bcdefgh & 1824abcde & $1904 \mathrm{ab}$ \\
\hline $1 \mathrm{D}$ & 596abcd & $624 \mathrm{abc}$ & 960mno & 994klmn & 1556ijklmn & 1618fghijklm \\
\hline $2 \mathrm{D}$ & 500efgh & 508efg & 1010jklmn & $960 \mathrm{mno}$ & 1510jklmn & $1487 \mathrm{klmn}$ \\
\hline $3 \mathrm{D}$ & 592abcd & $606 a b c$ & 1106ghijmn & 1006jklm & 1698cdefghijk & 1612fghijklm \\
\hline $4 \mathrm{D}$ & 580bcde & $634 a$ & 1226 bcdefgh & 1194cdefghi & 1806abcdefg & 1848abcde \\
\hline $5 \mathrm{D}$ & $525 \mathrm{defg}$ & $562 \mathrm{bcdef}$ & 1223 bcdefgh & 1251 abcdefg & 1748bcdefghi & 1813abcdef \\
\hline $6 \mathrm{D}$ & 572 bcde & 574 bcde & 1178defghi & 1082hijklmn & 1750abcdefghi & 1656efghijkl \\
\hline $7 \mathrm{D}$ & $550 \mathrm{bcdef}$ & $616 \mathrm{abc}$ & 1232 bcdefgh & 1214 bcdefgh & 1782abcdefgh & 1830abcde \\
\hline CS & 512defgh & $540 \mathrm{cdef}$ & 1137fghijkl & 1114ghijklm & 1681deghijk & 1665efghijkl \\
\hline Syn & 526defg & 578 bcde & $1346 \mathrm{abc}$ & 1336abcd & $1872 \mathrm{abcd}$ & $1914 a b$ \\
\hline
\end{tabular}

Values in bold are significantly different $(\mathrm{P} \geq 0.05)$. Values within RDW, ADW or TDW column with a similar letter are not significantly different. 
than CS either with or without infestation (Table 1). The rest of the substitution lines did not show differences from parental varieties or uninfested controls. The substitution lines that showed significantly lower ADW, RDW and TDW (5A, and 6A) compared to CS both with and without greenbug infestation, have been reported to contribute to antixenosis to greenbug and RWA infestation Castro et al. 2001) and a new gene for greenbug antixenotic resistance has been mapped on the 6A Castro et al 2005). These chromosomes may carry genes for constitutive defences that affect photosynthesis yielding a poor plant biomass, which made these genotypes unattractive for aphid feeding, or induce repellency. Since antixenosis to aphids has been associated with secondary compounds, the lower plant weights could be the result of the costs devoted by these genotypes to constitutive synthesis of secondary plant metabolites Martin et al.2003), distracting resources from plant growth and production regardless of the presence of insects Cipollini 2002). On the other hand, the $1 \mathrm{~A}, 1 \mathrm{D}$, and 7D substitution lines that are reported to carry aphid R genes McIntosh et al. 2003), showed no lowering in plant biomass under greenbug infestation.

Protein content showed highly significant differences between the control and infested plants of the parental lines (Table 2). Protein contents significantly increased as a result of greenbug infestation in the $1 \mathrm{~A}, 1 \mathrm{~B}, 7 \mathrm{~B}$ and $7 \mathrm{D}$ substitution lines compared to both parents and to their controls. The $7 \mathrm{~B}$ line showed the highest value and another seven substitution lines $(3 \mathrm{~A}, 6 \mathrm{~A}, 4 \mathrm{~B}, 1 \mathrm{D}, 3 \mathrm{D}, 4 \mathrm{D}$ and 5D) showed a significantly lower protein content than their controls and CS under infestation. The remaining substitution lines did not show significant differences between control and infested plants The 1A, 1B, 7B and 7D substitution lines were previously reported to reduce greenbug and/or RWA fertilities and longevities Castro et al. 2001). Increases in proteins have also been found in microbe infections (Martin et al.2003) and after Manduca sexta attack due to ethylene, jasmonic acid and salicylic acid elicited a significant number of genes involved with $\mathrm{N}$ metabolism under the stress of Manduca sexta attack Hui et al. 2003). Therefore the increases in protein content registered on 1A, 1B, 7B and 7D substitution lines could be then consequence of an enhanced protein synthesis necessary to support high enzymatic requirements due to the over-expression of genes in the downstream chain of events of plant defence that implies a greater metabolic activity under stress. The R genes carried by chromosome 7D Castro et al.2004 may interact with aphid elicitors to induce a cascade of transductional events involved with the higher protein synthesis that affect greenbug and RWA life cycles and fertilities (Castro et al. 2001). The remaining substitution lines (1A, 1B, 7B) have genes involved with $\mathrm{N}$ metabolism (McIntosh et al. 2003) that in the absence of aphid-specific $\mathrm{R}$ genes (located on Synthetic 7D), could induce proteins related with indirect defences (ie: defence proteins, peroxidases) that also affected aphid performance. Moreover, 121 candidate R-genes have been physically located with most mapping on the 1A, 1B and 7B chromosomes Dilbirligi and Gill 2003, Dilbirligi et al. 2004). Further characterization is necessary to find out the relationship between these R-gene candidates, $\mathrm{N}$ metabolism and the antibiosis to greenbug. 


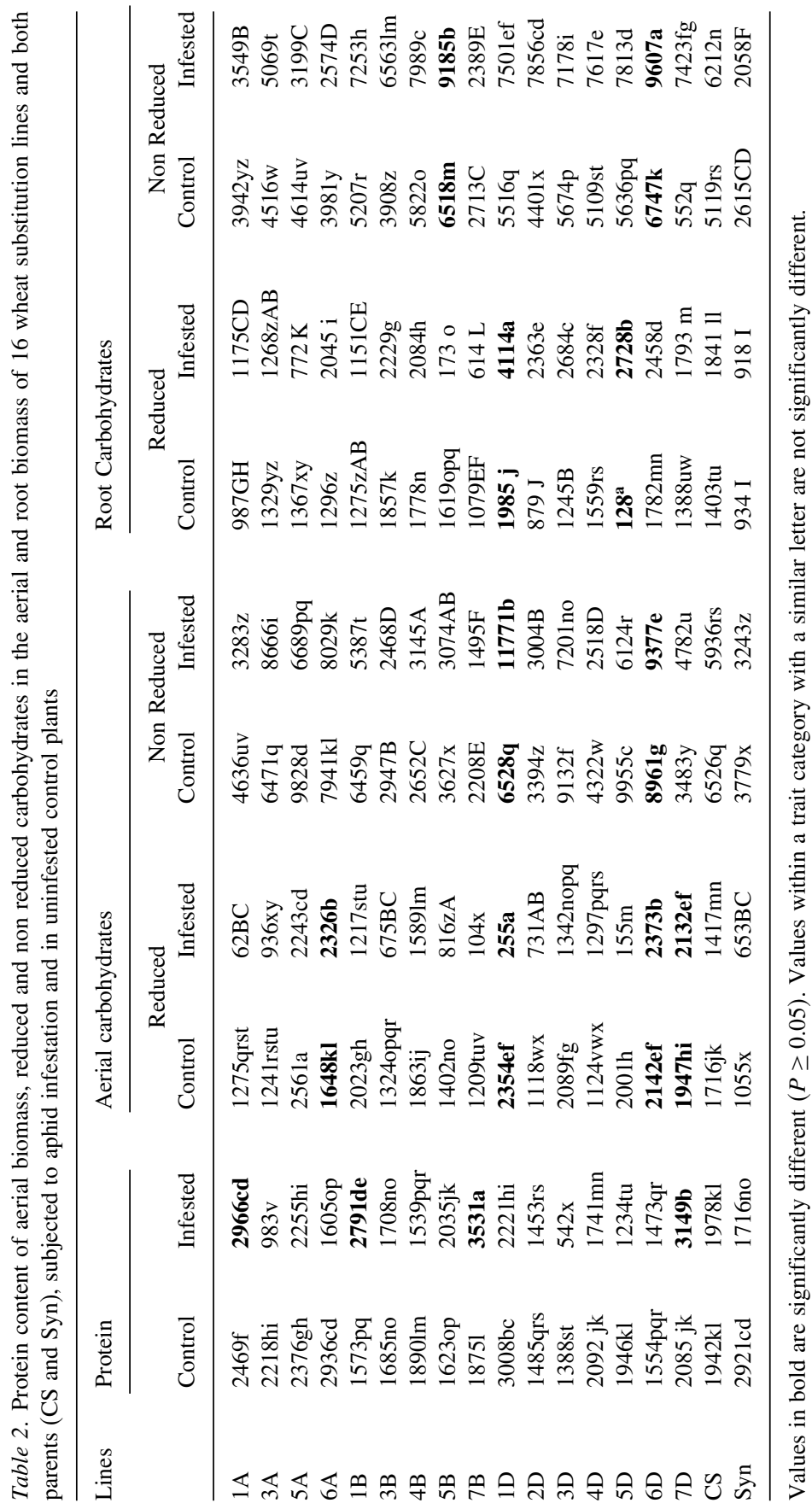


The parental lines showed significant differences in the reducing carbohydrates (RC) of the aerial tissues, with a significantly lower value for Syn (Table 2). Only infested plants of the 6A, 1D, 6D and 7D substitution lines showed a significantly higher RC than their controls and also than CS. The contents of non reducing carbohydrates (NRC) showed significant differences between control and infested plants of both parental lines, CS showing the highest value (Table 2). The greatest values of NRC in the infested plants were recorded for the 6D and 1D substitution lines with the latter showing the highest significant increases, consequently these substitution lines also showed the highest total aerial carbohydrates. There are significant differences in reducing carbohydrates in roots between control and infested plants of both parents RC values were significantly increased in CS and in most of the substitution lines Infested plants of the 1D and 5D lines showed the highest contents compared to CS and to their controls. There were significantly greater differences in non-reducing carbohydrates of the roots in control and infested plants of both parental lines, and CS showed the highest values (Table 2). Infestation significantly increased the NRC in CS and in most of the lines, with the highest values for $5 \mathrm{~B}$ and $6 \mathrm{D}$ The total carbohydrates resulted significantly higher in $1 \mathrm{D}$ and $6 \mathrm{D}$. Greenbug infestation was reported to produce a reduction in carbohydrates either due to ingestion or to chloroplast membrane injury (Al-Mousawi et al. 1983). Carbohydrate contents play an important role in the osmoregulation and osmoprotection of winter cereals. The current results show that the contents of different categories of carbohydrates were significantly different in several substitution lines subjected to aphid infestation. Most of the B and D genome substitution lines showed a significant increase in root carbohydrates but only 1D and 6D showed the highest increases in both the root and aerial parts under infestation. These substitution lines have been previously reported as tolerant to greenbug and RWA infestation Castro et al. 2001). Nonetheless, only chromosome 1D has been reported to carry aphid R genes (McIntosh et al. 2003) Possibly on chromosome $6 \mathrm{D}$ there are genes that cope with an increase in $\mathrm{C}$ metabolism. The metabolism of $\mathrm{C}$ is known to be one of the most reconfigurated under infestation (Ryan et al. 1987, Behle et al. 1994, Kessler and Baldwin 2002, Hui et al. 2003). The responses that could minimize the fitness consequences of insect attack represent the tolerance responses, a largely unstudied mechanism of defence Cipollini 2002). In the current research, the 1D and 6D lines showed significant increases in total carbohydrates of aerial and root parts, which could be related to an improved performance for nutrient uptake under stress. Nevertheless further research should be performed in order to understand the complex regulation of the tolerance to greenbug.

\section{ACKNOWLEDGEMENTS}

The authors wish to thank Ms. Mariana Barragan, and Ms. Mirna Ricciardi for the technical assistance. CONICET and British Council funded the current research. 


\section{REFERENCES}

Al-Mousawi AH, Richardson PE, Burton RL (1983) Ultrastructural studies of greenbug (Hemiptera: Aphididae) feeding damage to susceptible and resistant wheat cultivars. Ann Entomol Soc Am 76:964-971

Behle RW, Michels GJ, Gilstrap FE (1994) Greenbug (Homoptera: Aphididae) feeding effects on nonstructural carbohydrates in sorghum. Environ Entomol 23:965-970

Boyko E, Starkey S, Smith M (2004) Molecular genetic mapping of Gby, a new greenbug resistance gene in bread wheat. Theor Appl Genet 109:1230-1236

Bradford MM (1976) A rapid and sensitive method for the quantitation of microgram quantities of protein utilizing the principle of protein-dye binding. Anal Biochem 72:248-254

Burton RL (1986) Effect of greenbug (Homoptera: Aphididae) damage on root and shoot biomass of wheat seedlings. J Econon Entomol 79:633-636

Castro AM, Rumi CP, Arriaga HO (1988) Influence of greenbug on root growth of resistant and susceptible barley genotypes. Environ Exp Botany 28:61-72

Castro AM, Martín LM, Martín A, Arriaga HO, Tobes N, Almaraz L (1994) Screening for greenbug resistance in Hordeum chilense Roem et Schult. Plant Breed 112:151-159

Castro AM, Ramos S, Vasicek A, Worland A, Giménez D, Clúa A, Suárez E (2001) Identification of wheat chromosomes involved with different types of resistance against greenbug (Schizaphis graminum Rond) and the Russian wheat aphid (Diuraphis noxia Mordvilko). Euphytica 118:321-330

Castro AM, Worland AJ, Vasicek A, Ellerbrook C, Giménez DO, Tocho E, Tacaliti MS, Clúa A, Snape JW (2004) Mapping quantitative trait loci for resistance against greenbug and Russian wheat aphid. Plant Breed 123:361-365

Castro AM, Vasicek A, Manifesto M, Giménez DO, Tacaliti MS, Dobrovolskaya R, Röder MS, Snape JW, Börner A (2005) Mapping antixenosis genes on chromosome 6A of wheat to greenbug and to a new biotype of Russian wheat aphid. Plant Breed 123:229-233

Cipollini D (2002) Does competition magnify the fitness costs of induced responses in Arabidopsis thaliana? A manipulative approach. Oecologia 131:514-520

Clúa A, Castro A, Giménez D, Tacaliti M, Worland JA (2002) Chromosome effects in the endogenous contents of non-structural carbohydrates and proteins in wheat (Triticum aestivum). Plant Breed 121:142-145

Cronin D, Smith S (1979) A simple and rapid procedure for the analysis of reducing total and individual sugars in potato. Potato Research 22:99-105

Dilbirligi M, Gill KS (2003) Identification and analysis of expressed resistance gene sequences in wheat. Plant Mol Biol 53:771-787

Dilbirligi M, Erayman M, Sandhu D, Sidhu D, Gill KS (2004) Identification of wheat chromosomal regions containing expressed resistance genes. Genetics 166:461-481

Giménez DO, Rumi CP, Brocchi G, Castro AM, Almaraz LB, Arriaga HO (1990) P transport shortage in susceptible barley plants under 3 hrs of greenbug (Schizaphis graminum). Ann Plant Resistance to Insects Newsl 16:74-75

Giménez D, Castro A, Rumi C, Brocchi G, Almaraz L, Arriaga H (1997) Greenbug systemic effect on phosphate influx in barley (Hordeum vulgare L). Environ Exp Botany 38:109-116

Hermsmeier D, Schittko U, Baldwin I (2001) Molecular interactions between the specialist herbivore Manduca sexta (Lepidoptera, Sphingidae) and its natural host Nicotiana attenuata: I. Large-scale changes in the accumulation of growth- and defense-related plant mRNAs. Plant Physiol 125:687-700

Hoagland DR, Arnon D (1959) The water culture method for growing plants without soil. California Agriculture Experimental Station Circular 347:1-32

Hui D, Iqbal J, Lehmann K, Gase K, Saluz H, Baldwin I (2003) Molecular interactions between the specialist herbivore Manduca sexta and its natural host Nicotiana attenuata: V. Microarray analysis and further characterization of large-scale changes in herbivore-induced mRNAs. Plant Physiol 131:1877-1893

Kessler A, Baldwin I (2001) Defensive function of herbivore-induced plant volatile emissions in nature. Science 291:2141-2144 
Kessler A, Baldwin I (2002) Plant responses to insect herbivory: the emerging molecular analysis. Annu Rev Plant Biol 53:299-328

Law CN, Worland AJ (1996) Intervarietal chromosome substitution lines in wheat-revisited. Euphytica 89:1-10

Martin G, Bogdanove A, Sessa G (2003) Understanding the functions of plant disease resistance proteins. Annu Rev Plant Biol 54:23-61

McIntosh RA, Yamazaki Y, Devos K, Dubcovsky J, Rogers J, Appels R (2003) Catalogue of gene Symbols for wheat http://wwwgrsnigacjp/wheat/komugi/genes/

Ryan JD, Johnson R, Eikenbary R, Dorschner J (1987) Drought/greenbug interactions: photosynthesis of greenbug resistant and susceptible wheat. Crop Sci 27:283-288

SAS Institute (1998) SAS/STAT guide for personal computers, version 6.03, carry NC 